Review

\title{
Social Media and Alcohol: Summary of Research, Intervention Ideas and Future Study Directions
}

\author{
Megan A. Moreno ${ }^{1, *}$, Jon D’Angelo ${ }^{2}$ and Jennifer Whitehill ${ }^{3}$ \\ ${ }^{1}$ Pediatrics, University of Washington, Seattle, WA 98105, USA; E-Mail: megan.moreno@seattlechildrens.org \\ ${ }^{2}$ Communication Arts, University of Wisconsin-Madison, Madison, WI 53706, USA; E-Mail: jdangelo03@gmail.com \\ ${ }^{3}$ Public Health, University of Massachusetts, Amherst, MA 01003, USA; E-Mail: jenwh@uw.edu \\ * Corresponding author
}

Submitted: 14 December 2015 | Accepted: 16 March 2016 | Published: 16 June 2016

\begin{abstract}
Alcohol content is frequently displayed on social media through both user-generated posts and advertisements. Previous work supports that alcohol content on social media is influential and often associated with offline behaviors for adolescents and young adults. Social media may have a role in future alcohol intervention efforts including identifying those at risk or providing timely prevention messages. Future intervention efforts may benefit from an affordance approach rather than focusing on a single platform.
\end{abstract}

\section{Keywords}

adolescents; alcohol; college students; Facebook; social media; young adults

\section{Issue}

This review is part of the issue "Adolescents in the Digital Age: Effects on Health and Development", edited by Dan Romer (University of Pennsylvania, USA).

(C) 2016 by the authors; licensee Cogitatio (Lisbon, Portugal). This article is licensed under a Creative Commons Attribution 4.0 International License (CC BY).

\section{Introduction: Social Media and Adolescents}

Social media are often described as media that are interactive, allowing exchange and modification of information between creators and consumers. Social media are defined as "forms of electronic communication through which users create online communities to share information, ideas, messages and other content" (Merriam-Webster, 2015). Social media include social networking sites such as Facebook, Instagram and Twitter, which are accessible via web-browsers or dedicated mobile applications (apps), as well as apps that promote interaction such as multiplayer games; these formats are diverse and yet share many similar features. The multi-directional nature of social media communication differentiates social media from traditional mass media, traditional video games, and from the earlier days of the internet when websites generally provided content in a one-directional manner (Kaplan \& Haenlein, 2010).
Social media are hugely popular and frequently accessed by adolescents and young adults (Duggan, Ellison, Lampe, Lenhart, \& Madden, 2014; Lenhart, 2015). Adolescents have been dubbed the "digital generation" or "digital natives" given that they have grown up with access to computers and the internet from an early age (Palfrey \& Gasser, 2012). Today, over $90 \%$ of adolescents report going online every day and almost a quarter of teens report that they go online "almost constantly" (Lenhart, 2015). In most cases, a social media user creates an account, links to a network of other individual users or groups, and uses the site or app to share content with and access information from other users (Kietzmann, Hermkens, McCarthy, \& Silvestre, 2011). Adolescents typically interact with several favorite social media sites, and thus maintain a "social media portfolio" including social networking sites such as Facebook, photo sharing sites such as Instagram and blogging sites such as Tumblr (Lenhart, 2015).

The evolution of social media over the past decade 
has provided adolescents with numerous benefits, including access to information, social support and farreaching communication tools (Ellison, Steinfield, \& Lampe, 2007; Ellison, Steinfield, \& Lampe, 2011; Valenzuela, Park, \& Kee, 2009). Social media can provide enhanced opportunities to explore and experiment with one's identity and social networks. There are also risks to technology use which include overuse at the expense of offline activities, exposure to inappropriate content and negative social interactions such as cyberbullying (Collins, Martino, \& Shaw, 2011; Mitchell, Sabina, Finkelhor, \& Wells, 2009). Both these risks and rewards have been amplified over the past five years as it has become normative for most adolescents to access these spaces $24 / 7$ from their pocket using mobile devices (Lenhart, 2015).

This paper will focus on the intersection of alcohol content and social media, as the majority of research regarding health risk behaviors and social media has been focused in this area.

\section{Alcohol Content Displayed on Social Media}

Social media are a source of exposure to two important sources of influence associated with youth alcohol use-peer alcohol behavior (Ali \& Dwyer, 2010; Mundt, Mercken, \& Zakletskaia, 2012) and alcohol advertising (Jernigan, 2006, 2011). Thus, adolescents may be exposed to alcohol content created by peers as social media users, or advertisements created by corporations and designed to be influential in the social media context.

\subsection{User-Generated Alcohol Content}

Content posted by adolescents and young adults is likely to be seen by peers as well as potentially viewed by younger users of these sites. Studies in this area have examined a variety of social media platforms, early studies in this area focused on MySpace and Facebook. Several studies have illustrated that adolescents' displays on these two sites frequently include portrayal of health risk behaviors related to alcohol, other substances, and sexual behaviors (Hinduja \& Patchin, 2008; McGee \& Begg, 2008; Moreno, Parks, \& Richardson, 2007; Moreno, Parks, Zimmerman, Brito, \& Christakis, 2009). Alcohol displays may include text (i.e. "got soooo drunk last night"), photographs depicting alcohol consumption, or links to alcohol-related groups or companies (Egan \& Moreno, 2011; Moreno, Briner, et al., 2010).

Early studies in this area found that adolescents who displayed health risk behaviors on social media did so in patterns that were consistent with patterns of offline reporting by adolescents. For example, adolescents who display one health risk behavior on social media, such as sexual activity, are more likely to display other behaviors such as alcohol use (Moreno, Parks, et al., 2009). Further, a previous study found that adolescents were more likely to display references to sexual behavior if a peer displayed similar references (Moreno, Brockman, Rogers, \& Christakis, 2010). Thus, risk behaviors may be displayed online within peer groups, just as offline peer groups commonly report engagement in similar behaviors. While displayed health risk behaviors are common on social media sites, negative consequences of these behaviors are not frequently noted. One study of older adolescents found that displays of negative consequences of alcohol use, such as hangovers or embarrassment, on social media were rare (Moreno, Briner, et al., 2010).

As new social media sites such as Twitter and Instagram have emerged, a small number of studies have examined alcohol-related content on these sites. A study of Twitter found that the majority of content was positive towards alcohol and that most content was generated by individual users rather than companies or corporations (Cavazos-Rehg, Krauss, Sowles, \& Bierut, 2015). Previous studies in other health-related areas have illustrated that Twitter can be used to identify alcohol-related behaviors or intentions across populations (Chew \& Eysenbach, 2010; Signorini, Segre, \& Polgreen, 2011). One study examined keywords that are synonyms for the word drunk among a sample of over 5 million tweets from users selected to be geographically representative of the U.S. Tweets related to intoxication peaked between the hours of $10 \mathrm{pm}$ and $2 \mathrm{am}$ in the user's local time, and were more prevalent on Friday and Saturday nights (West et al., 2012). They also found the proportion of all tweets that were intoxication-related over the New Year's holiday weekend was $0.53 \%$ compared to $0.34 \%$ during non-holiday weekends. These findings parallel studies that emphasize the increased risk for alcohol problems that occur during holidays and other specific events (Neighbors et al., 2011). These studies illustrate that social media can be used to identify times in which high-risk behaviors are escalated, which may be valuable targets for interventions.

\subsection{Unregulated Marketing on Social Media}

In addition to user-generated content, young people are exposed to alcohol advertising on social media. There is growing concern about the extent to which adolescents and young adults are exposed to alcohol marketing on social media websites. Research from both the US and the UK indicate that the major alcohol brands maintain a presence on Facebook, Twitter, and YouTube (Jernigan \& Rushman, 2013; Winpenny, Marteau, \& Nolte, 2013).

Analysis of social media marketing for leading alcohol brands in the United Kingdom indicated certain tactics were most common, including promoting an 
offline branded event (e.g. at a club or sporting event), interactive games, sponsored online events, and invitations to drink (Nicholls, 2012). Social media present a concerning new venue for alcohol advertisers given their ability to target messages to particular users and creating lasting connections with consumers (Jernigan \& Rushman, 2013), which can lead to increased positive attitudes, intentions or behaviors towards alcohol. Software is available that could allow alcohol brands to ask for age verification before a user can become a follower of the brand account. Such software typically requires the user to enter a birth date, if the birth date shows that the user is not over the legal age to purchase alcohol then the user cannot access the site. However, a recent inquiry into alcohol-branded sites found that none used any thirdparty age verification beyond self-reported age (Jernigan \& Rushman, 2013).

A recent study evaluated alcohol marketing on Twitter and Instagram using 20 fictitious profiles with ages between 13 and 21 years (Barry et al., 2015). In all cases, the user profiles could access, view and interact with alcohol industry content on both Twitter and Instagram. On Twitter, only the profiles that reported age 21 could "follow" an alcohol industry page, and these pages received almost 2,000 tweets in the month of evaluation from those companies. There were no age restrictions in following alcohol brand content on Instagram. Thus, the authors concluded that accessing industry-sponsored alcohol content on these two sites is easily available to youth of all ages.

\subsection{Influence of Displayed Alcohol on Social Media}

Decades of research rooted in observational theory have established strong links between what adolescents see and what behaviors they choose (Bandura, 1986). Equally strong are links between traditional media such as television or movies and health behaviors among adolescents (Dalton et al., 2003; Dalton et al., 2009; Gidwani, Sobol, DeJong, Perrin, \& Gortmaker, 2002; Titus-Ernstoff, Dalton, Adachi-Mejia, Longacre, \& Beach, 2008). Studies have shown that exposure to alcohol, tobacco or sexual behaviors in traditional media is associated with initiation of these behaviors (Dalton et al., 2009; Gidwani et al., 2002; Klein et al., 1993; Robinson, Chen, \& Killen, 1998).

However, social media differs from traditional media in that the "stars" and role models presented in social media are usual everyday peers, and emulation of a peer may feel and be more achievable than emulation of a movie star. Thus, social media combines the influence of peers and that of media, and thereby represents a powerful motivator of behavior. A previous study found that adolescents who view alcohol references on their peers' Facebook profiles find these to be believable and influential sources of information
(Moreno, Briner, Williams, Walker, \& Christakis, 2009). Further, adolescents who perceive that alcohol use is normative based on Facebook profiles are more likely to report interest in initiating alcohol use (Litt \& Stock, 2011).

The Facebook Influence Model was developed through a Concept Mapping Process involving adolescents and young adults as stakeholders (Trochim \& Kane, 2005). This validated process includes several steps of data collection and synthesis applying stakeholder input. The final product is a Concept Map, a visual map showing key concepts and how they relate to each other. The Facebook Influence Model includes 13 clusters that illustrate ways in which Facebook is influential; clusters include "influence on identity", "connection to people" and "social norms." Table 1 describes the cluster names and example items within each cluster. One young adult participant described that "uploading photos contributes to setting the social norm. I don't think we upload photos to set social norms, we upload photos to share and connect with other people and a byproduct of that is setting social norms" (Moreno, Kota, Schoohs, \& Whitehill, 2013). While more information is clearly needed to understand the influence of social media on health risk behaviors, these early studies provide support for further research.

\section{Associations between Online Content and Offline Behaviors}

An adolescent posts on Facebook: "Coors is my favorite beer!" The media practice model describes that youth seek out media that represent who they are, or who they wish to be (Brown, 2000). Thus, displayed alcohol content may reflect positive attitudes, intentions or behaviors. For the post regarding Coors, this may mean that an adolescent has engaged in alcohol use, hopes to engage in alcohol use, or wishes to impress peers. Previous studies have investigated the meaning of these posts to the youth who display them. In one study, older adolescents whose Facebook posts suggested problem drinking behaviors were more likely to score as at risk on a problem drinking screen (Moreno, Christakis, Egan, Brockman, \& Becker, 2011). Another study examined college student posts on Facebook about attending an alcoholthemed event and found that these students were highly likely to attend that event and drink at levels above the binge drinking threshold (Moreno, Kacvinsky, Pumper, Wachowski, \& Whitehill, 2014). Interestingly, in this study many college students displayed their intention to attend the event prior to the event taking place, suggesting that this displayed information could be used by universities to send targeted prevention messages to these students. 
Table 1. Clusters and concepts within the Facebook Influence Model.

\begin{tabular}{|c|c|c|}
\hline Key groups & Clusters & Example items within cluster \\
\hline \multirow[t]{16}{*}{ Connection } & Accessible and adaptable & $\begin{array}{l}\text {-Largest network in human history } \\
\text {-Easy to use and navigate } \\
\text {-Widely known and talked about }\end{array}$ \\
\hline & Information and data & -Huge database of information \\
\hline & & -Compiled data from millions of individuals \\
\hline & & -News feature \\
\hline & Promotion: Events, groups & -Ability to plan influential events such as protests or sit-ins \\
\hline & and networking & $\begin{array}{l}\text {-Statuses provide a way to blog instantly about events or } \\
\text { political topics }\end{array}$ \\
\hline & & -Every company uses it to promote business or provide deals \\
\hline & "Everyone you know has it" & -Allows people to constantly stay updated with other's lives \\
\hline & & -Way to get to know acquaintances almost instantly \\
\hline & & -Keep in touch with people you wouldn't call or text \\
\hline & Far reaching & -Ability to reach many people with one website \\
\hline & & -Can reach anyone, young and old, rich and poor \\
\hline & & -Bonding across cultures and distances \\
\hline & Fast Communication & -Feel connected and in the loop constantly \\
\hline & & -Puts everyone you know and what they're doing in one place \\
\hline & & -Updates on people's lives faster than with a cell phone \\
\hline \multirow[t]{7}{*}{ Identification } & Identity construction & -Freedom to express things and let it be heard \\
\hline & & -Present the best side of yourself \\
\hline & & -Show off accomplishments to everyone you are friends with on \\
\hline & & Facebook, not just close friends \\
\hline & Identity reflection & -Provides others with pictures that can influence perceptions \\
\hline & & $\begin{array}{l}\text {-Display aspects of yourself that you wouldn't share in offline life } \\
\text { (sexuality, substance use) }\end{array}$ \\
\hline & & $\begin{array}{l}\text {-Wonder if you should be doing what you see everyone doing in } \\
\text { pictures }\end{array}$ \\
\hline \multirow[t]{6}{*}{ Comparison } & Curiosity about others & $\begin{array}{l}\text {-Can know what people are up to without asking them about it } \\
\text { and without them knowing you know }\end{array}$ \\
\hline & & -Creep culture \\
\hline & & -See who associates with whom with pictures and comments \\
\hline & $\begin{array}{l}\text { Unique aspects of Facebook } \\
\text { that impart social norms }\end{array}$ & $\begin{array}{l}\text {-Reinforces beliefs or opinions by seeing that others hold same } \\
\text { beliefs or opinions }\end{array}$ \\
\hline & & -Can see what is popular by observation \\
\hline & & -Can follow norms \\
\hline \multirow{9}{*}{$\begin{array}{l}\text { Facebook as an } \\
\text { experience }\end{array}$} & Distractions & -Procrastination \\
\hline & & -Addictive \\
\hline & & -Huge distraction \\
\hline & Positive experiences & -Facebook is referenced in daily life \\
\hline & & -Provides entertainment at any time \\
\hline & & -Status updates can promote a good mood \\
\hline & Negative experiences & $\begin{array}{l}\text {-Changes the nature of communication from face-to-face to } \\
\text { screen-to-screen }\end{array}$ \\
\hline & & -People willing to sacrifice privacy \\
\hline & & -Inspires competition in people \\
\hline
\end{tabular}

A recent study examined underage college students' initial, or first-time, alcohol displays on Facebook and found that location of a post on the Facebook profile mattered when interpreting its meaning (Moreno, Cox, Young, \& Haaland, 2015). Displaying an initial alcohol reference as a cover photo or profile picture was associ- ated with multiple binge drinking episodes in the past month. In contrast, displaying an initial alcohol reference as a Facebook "like" was less likely to identify a student engaging in binge or problematic alcohol use. In this study, photos were generally more likely to identify problem alcohol use compared to text-based information. 


\section{Potential Role for Social Media in Alcohol-Related Interventions}

Despite the use broad reach of social media, the literature is scant on interventions using social media to reduce harmful alcohol consumption. Consideration of previous work can be used to suggest future directions for social media interventions.

\subsection{Facebook}

Based on previous work that illustrates links between displayed alcohol references and self-reported alcohol behaviors on Facebook (Moreno et al., 2011), one possible avenue for intervention could involve identifying individuals who may be at risk for alcohol-related problems based on the social media content they post. These displays may represent innovative means to identify at-risk individuals and prompt them to undergo further screening and intervention. Further, approaches could establish friending links with at-risk individuals so that ongoing monitoring and two-way communication is possible.

Few studies have been done in this area, a previous intervention using MySpace found that a message from a physician was successful in encouraging adolescents to remove sexual content from their public profiles, but did not affect substance use content (Moreno, Vanderstoep, et al., 2009). Important issues to consider for interventions targeting unique individuals include consideration of changing behaviors posted on social media, as in the previous intervention example, versus changing behaviors offline. Further considerations include how to identify individuals given variation in privacy settings and the fact that the identity of social media users is not always known.

Facebook also provide opportunities to link usergenerated content to triggered Facebook advertisements. The Facebook Influence Model describes the influence of "identity development" on Facebook, and interventions could build upon this source of influence (Moreno, Kota, et al., 2013). Researchers could consider linking Facebook advertisements to a user's displayed alcohol content. The advertisement could provide messages for a user to consider whether they want alcohol content as part of their online or offline identity. For example, an advertisement could be triggered by keywords related to "intoxication" on Facebook, and could include a message such as "Do you really want being drunk to be part of your identity?"

\subsection{Twitter}

The relatively large volume of public content on Twitter raises the possibility of an automated search system that would identify tweets indicating risk of alcoholrelated problems and respond with a link to resources or services. An ongoing study to determine feasibility of responding to tweets mentioning the words such as "drink," "drunk," "drunk drive," found that unless the sender of the tweets is already a follower (or followed by) the targeted user, any tweets with a link are blocked by Twitter's spam filter (Whitehill, Moreno, \& Rivara, 2014). Thus, the possibility of a public health agency conducting such an effort may be limited. However, additional creative approaches may include enlisting influential Twitter users, such as musicians or celebrities, or even users with a wide social network, to promote public health efforts. Further efforts to understand and test the ability to use various social media sites for automated two-way communication to reduce alcohol risk are needed.

\subsection{Social Media Advertisements}

Another possible approach is to use social media for social marketing. In this way, social media could be used in a similar way that traditional media outlets have promoted responsible alcohol use and increased awareness alcohol-related harm. Advertisements could be pegged to the same keywords used by alcohol beverage advertising, with the goal of reaching the same target audiences and providing educational messaging or links to online interventions.

While the possibilities of achieving targeted, farreaching and cost-effective interventions with social media is compelling, more research is needed to understand key factors that would make these intervention approaches acceptable to adolescents and young adults.

\subsection{Partnering with Adolescents and Young Adults}

The world of social media-including evolution of new sites, new hashtags and new adolescent slang termsmoves fast. Thus, partnering with adolescents and young adults in the design of studies and interpretation of findings is critical. A previous study examined young adults' preferences for use of social media in research and found that approximately three quarters of participants were supportive of using social media for research, and those who had concerns often cited privacy as a central issue (Moreno, Grant, Kacvinsky, Moreno, \& Fleming, 2012). Another study found that young adults described communication style and approach as critical issues in acceptance of a social media alcohol intervention (Moreno, Grant, Kacvinsky, Egan, \& Fleming, 2012). Partnering with adolescents and young adults in the design of studies and interventions is a crucial component of creating tools that are acceptable to the target population.

\section{Future Research Directions}

Adolescents and young adult are uniquely positioned 
to be particularly vulnerable to the effects of social media: they are at once early adopters, nearly ubiquitous users, and highly susceptible to peer influences (Ellison et al., 2007; Lenhart \& Madden, 2007; Lenhart, Madden, \& Hitlin, 2005; Lenhart, Purcell, Smith, \& Zickuhr, 2010). As the field of social media research is still in its infancy, further work is needed in several arenas.

First, studies that expand and deepen observational research on social media sites are needed. Past studies have described content and posting timing on sites such as MySpace, Facebook and Twitter (Hinduja \& Patchin, 2008; Moreno, Briner, et al., 2010; Moreno, Parks, et al., 2009; West et al., 2012). However, studies that fully harness the social aspects of social media by studying interactions between peers, distribution of content through a social network, or interactions between adolescents and adults are needed. Previous work suggested that that "currently research is preliminary and descriptive, and we need innovative methods and detailed in-depth studies to gain greater understanding of young people's mediated drinking cultures and commercial alcohol promotion" (McCreanor et al., 2013). These types of studies would help deepen our understanding of how alcohol content is distributed and shared through networks, and potentially identify intervention partners who have access to and are willing to confront adolescents and young adults regarding displayed references to alcohol.

Second, the interactive nature of social media sites provides new opportunities for interventions. Such interventions must be developed with an understanding of the privacy settings within each network. Only individuals who are able to view the content and comfortable with communicating about it would be able to conduct such an intervention. Understanding whether parents, teachers, college resident advisors, and other influential adults are privy to young people's displays of alcohol content on social media is an area for future inquiry. For example, if a parent sees a reference to problem alcohol use on their child's Facebook profile, it is possible that reference is positively associated with engagement in problem drinking. It is likely that having parent-child communication prompted by that social media reference would be important at that time. Preliminary work has explored communication strategies for these encounters and potential intervention opportunities (Moreno et al., 2012; Park \& Calamaro, 2013; Whitehill, Brockman, \& Moreno, 2013). However, further work is needed to understand how this knowledge can be translated into clinical practice or educational interventions appropriate to different settings, such as schools, clinics or universities (George, Rovniak, \& Kraschnewski, 2013).

Third, in considering future studies and interventions in particular, we need to move beyond focusing on a specific platform and better understand key as- pects social media use that transcend these platforms. Affordances are often described as properties of artifacts that can be recognized by users and contribute to their function (Zhao, Liu, Tang, \& Zhu, 2013). Perceived affordances can also be conceptualized as "design aspects of objects that suggest to the user how the object should be used," (Zhao et al., 2013). A simple example is that the design elements of a chair suggest to a person that the object could be used for sitting. An affordance approach can be useful for research and intervention design because while popular websites may change, issues that may arise with use of these websites can be predicted by considering key concepts such as anonymity that are inherent in the design of the website (Bazarova, 2011; Choi \& Toma, 2014; Halpern \& Gibbs, 2013; Steinfield, Ellison, \& Lampe, 2008).

Using an affordances approach to understand aspects and functions of sites that cut across different platforms is a promising approach to creation of research studies and interventions that are not focused on a single site. Affordances may include identity affordances (Majchrzak, Faraj, Kane, \& Azad, 2013), which include whether or not the social media site requires using a real name (or some version of it). Facebook requires a real name, while Twitter and Instagram do not. Social affordances include whether the site promotes a sense of belonging to a group, such as a group focused on a particular interest, experience, social group or religion (Lundby, 2011). Further, some social media sites provide specific tools which allow the user to identify members of their group and enhance a feeling of belonging, such as "tagging" (Cook \& Pachler, 2012). Hashtags (i.e. content labeled with a \# sign) are commonly used on Twitter and Instagram and enhance belonging. Cognitive affordances may include using social media tools to expand one's learning. Examples may include increasing awareness of news events using Twitter, seeking out homework-related information on Wikipedia or learning how to play a piano piece using YouTube. These affordances may be particularly useful for adolescents who may not traditionally get exposed to this information offline (Zhao et al., 2013). Using an affordance approach, researchers can identify what types of affordances their intervention approaches utilize, and identify appropriate social media sites for the intervention that feature these affordances.

Finally, in all future studies involving social media sites, attention to two factors will be critical. One is attention to privacy settings on sites and users' expectations for protection of their confidentiality. Previous work has illustrated that older adolescents are willing to interact with others regarding their displayed health risk behaviors on social media sites (Moreno et al., 2012), however, social media sites may vary in users' expectations for privacy. A second critical factor is attention to approaching social media sites with the same ethical and regulatory rigor that is expected in of- 
fline studies involving human subjects. Several guidelines have been published that identify best practices in study design and working with institutional research boards (Moreno, Fost, \& Christakis, 2008; Moreno, Goniu, Moreno, \& Diekema, 2013; Sixsmith \& Murray, 2001; Zimmer, 2010).

This paper has focused on the intersection of alcohol content and social media, as the majority of research regarding health risk behaviors and social media has been in this area. However, research on other areas of substance use, such as the legalization of marijuana in two US states, newer substance use practices such as edible marijuana and potentials for participant recruitment and online interventions in the area of drug use also represent important and promising areas of research. Social media can be used to track epidemiologic trends in the growth of new substances using social media chatter as a proxy. A previous study used Twitter to track trends in a viral outbreak (Chew \& Eysenbach, 2010). It is exciting to consider the rapid growth in social media and alcohol studies over the past ten years, and the multidisciplinary researchers involved in these efforts. Social media have the potential to enhance our observational studies of alcohol behaviors, and the facilitate creation and dissemination of effective interventions to reduce the harms associated with alcohol use.

\section{Conflict of Interests}

The authors declare no conflict of interests.

\section{References}

Ali, M. M., \& Dwyer, D. S. (2010). Social network effects in alcohol consumption among adolescents. Addictive Behaviors, 35(4), 337-342. doi:10.1016/j.addbeh. 2009.12.002

Bandura, A. (1986). Social foundations of thought and action: A social cognitive theory. Englewood Cliffs: Prentice Hall.

Barry, A. E., Bates, A. M., Olusanya, O., Vinal, C. E., Martin, E., Peoples, J. E., . . Montano, J. R. (2015). Alcohol marketing on Twitter and Instagram: Evidence of directly advertising to youth/adolescents. Alcohol and Alcoholism. doi:10.1093/alcalc/agv128

Bazarova, N. N. (2011). Public intimacy: Disclosure interpretation and social judgments on Facebook. Journal of Communication, 62, 815-832.

Brown, J. D. (2000). Adolescents' sexual media diets. Journal of Adolescent Health, 27(2 Suppl), 35-40. doi:S1054139X00001415 [pii]

Cavazos-Rehg, P., Krauss, M. J., Sowles, S. J., \& Bierut, L. J. (2015). "Hey everyone, I'm drunk." An evaluation of drinking-related Twitter chatter. Journal of Studies on Alcohol and Drugs, 76, 635-643.

Chew, C., \& Eysenbach, G. (2010). Pandemics in the age of Twitter: Content analysis of Tweets during the 2009 H1N1 outbreak. PLoS One, 5(11), e14118. doi:10.1371/journal.pone.0014118

Choi, M., \& Toma, C. (2014). Social sharing through interpersonal media: Patterns and effects on emotional well-being. Computers and Human Behavior, 36(530-541).

Collins, R. L., Martino, S., \& Shaw, R. (2011). Influence of new media on adolescent sexual health: Evidence and opportunities. Retrieved from http://www.rand. org/pubs/working_papers/WR761.html

Cook, J., \& Pachler, N. (2012). Online people tagging: Social (mobile) network (ing) services and work-based learning. British Journal of Educational Technology, 43, 711-725.

Dalton, M. A., Beach, M. L., Adachi-Mejia, A. M., Longacre, M. R., Matzkin, A. L., Sargent, J. D., . . TitusErnstoff, L. (2009). Early exposure to movie smoking predicts established smoking by older teens and young adults. Pediatrics, 123(4), e551-558. doi:123/ 4/e551 [pii]10.1542/peds.2008-2102

Dalton, M. A., Sargent, J. D., Beach, M. L., Titus-Ernstoff, L., Gibson, J. J., Ahrens, M. B., . . Heatherton, T. F. (2003). Effect of viewing smoking in movies on adolescent smoking initiation: A cohort study. Lancet, 362(9380), 281-285. doi:S0140-6736(03)13970-0 [pii] 10.1016/S0140-6736(03)13970-0

Duggan, M., Ellison, N. B., Lampe, C., Lenhart, A., \& Madden, M. (2014). Social media update 2014. Retrieved from http://www.pewinternet.org/2015/01/ 09/social-media-update-2014

Egan, K. G., \& Moreno, M. A. (2011). Alcohol references on undergraduate males' Facebook profiles. American Journal of Men's Health, 413-420. doi:155798 8310394341[pii]10.1177/1557988310394341

Ellison, N. B., Steinfield, C., \& Lampe, C. (2007). The benefits of Facebook "friends": Social capital and college students' use of online so.cial network sites. Journal of Computer-Mediated Communication, 12(4), 1143116

Ellison, N. B., Steinfield, C., \& Lampe, C. (2011). Connection strategies: Social capital implications of Facebook-enabled communication practices. New Media \& Society, 13(6), 873-892. doi:10.1177/14614448103 85389

George, D. R., Rovniak, L. S., \& Kraschnewski, J. L. (2013). Dangers and opportunities for social media in medicine. Clinical Obstetrics and Gynecology, 56(3), 453462. doi:10.1097/GRF.0b013e318297dc3800003081201309000-00006 [pii]

Gidwani, P. P., Sobol, A., DeJong, W., Perrin, J. M., \& Gortmaker, S. L. (2002). Television viewing and initiation of smoking among youth. Pediatrics, 110(3), 505-508. Retrieved from http://www.ncbi.nlm.nih. gov/entrez/query.fcgi?cmd=Retrieve\&db=PubMed \& dopt=Citation\&list_uids $=12205251$

Halpern, D., \& Gibbs, J. L. (2013). Social media as a cata- 
lyst for online deliberation? Exploring the affordances of Facebook and YouTube. Computers in Human Behavior, 29(3), 1159-1168.

Hinduja, S., \& Patchin, J. W. (2008). Personal information of adolescents on the Internet: A quantitative content analysis of MySpace. Journal of Adolescence, 31(1), 125-146. doi:S0140-1971(07)00054-1

Jernigan, D. H. (2006). Importance of reducing youth exposure to alcohol advertising. Archives of Pediatrics and Adolescent Medicine, 160(1), 100-102. doi:160/ 1/100[pii]10.1001/archpedi.160.1.100

Jernigan, D. H. (2011). Framing a public health debate over alcohol advertising: The center on alcohol marketing and youth 2002-2008. Journal of Public Health Policy, 32(2), 165-179. doi:10.1057/jphp.2011.5jphp 20115 [pii]

Jernigan, D. H., \& Rushman, A. E. (2013). Measuring youth exposure to alcohol marketing on social networking sites: Challenges and prospects. Journal of Public Health Policy, 35(1), 91-104. doi:10.1057/jphp. 2013.45

Kaplan, A. M., \& Haenlein, M. (2010). Users of the world, unite! The challenges and opportunities of Social Media. Business Horizons, 53(1), 59-68. doi:http:// dx.doi.org/10.1016/j.bushor.2009.09.003

Kietzmann, J. H., Hermkens, K., McCarthy, I. P., \& Silvestre, B. S. (2011). Social media? Get serious! Understanding the functional building blocks of social media. Business Horizons, 54(3), 241-251.

Klein, J. D., Brown, J. D., Childers, K. W., Oliveri, J., Porter, C., \& Dykers, C. (1993). Adolescents' risky behavior and mass media use. Pediatrics, 92(1), 24-31. Retrieved from http://www.ncbi.nlm.nih.gov/pubmed/ 8516081

Lenhart, A. (2015). Teens, social media \& technology overview 2015. Retrieved from http://www.pewinter net.org/2015/04/09/teens-social-media-technology2015

Lenhart, A., \& Madden, M. (2007). Social networking sites and teens: An overview. Retrieved from http://www.pewinternet.org/pdfs/PIP_SNS_Data_M emo_Jan_2007.pdf

Lenhart, A., Madden, M., \& Hitlin, P. (2005). Teens and technology: Youth are leading the transition to a fully wired and mobile nation. Retrieved from http://www.pewinternet.org/pdfs/PIP_Teens_Tech_ July2005web.pdf

Lenhart, A., Purcell, K., Smith, A., \& Zickuhr, K. (2010). Social media and young adults. Retrieved from http://www.pewinternet.org/Reports/2010/SocialMedia-and-Young-Adults.aspx

Litt, D. M., \& Stock, M. L. (2011). Adolescent alcoholrelated risk cognitions: The roles of social norms and social networking sites. Psychology of Addictive Behaviors, 24(4), 708-713. doi:2011-11461-001 [pii]10. $1037 / \mathrm{a} 0024226$

Lundby, K. (2011). Patterns of belonging in ofline/offline interfaces of religion. Information, Communication and Society, 14, 1219-1235.

Majchrzak, A., Faraj, S., Kane, G., \& Azad, B. (2013). The contradictory influence of social media affordances on online communal knowledge sharing. Journal of Computer Mediated Communication, 19, 38-55.

McCreanor, T., Lyons, A., Griffin, C., Goodwin, I., Barnes, H., \& Hutton, F. (2013). Youth drinking cultures, social networking and alcohol marketing: Implications for public health. Critical Public Health, 23(1), 110120.

McGee, J. B., \& Begg, M. (2008). What medical educators need to know about "Web 2.0". Medical Teacher, 30(2), 164-169.

Merriam-Webster. (2015). Definition of social media. Retrieved from http://www.merriam-webster.com/ dictionary/social\%20media

Mitchell, K. J., Sabina, C., Finkelhor, D., \& Wells, M. (2009). Index of problematic online experiences: Item characteristics and correlation with negative symptomatology. CyberPsychology \& Behavior, 12(6), 707-711.

Moreno, M. A., Briner, L. R., Williams, A., Walker, L., Brockman, L. N., \& Christakis, D. A. (2010). A content analysis of displayed alcohol references on a social networking web site. Journal of Adolescent Health, 47(2), 168-175.

Moreno, M. A., Briner, L. R., Williams, A., Walker, L., \& Christakis, D. A. (2009). Real use or "real cool": Adolescents speak out about displayed alcohol references on social networking websites. Journal of Adolescent Health, 45(4), 420-422. doi:S1054-139X(09) 00165-7

Moreno, M. A., Brockman, L. N., Rogers, C. B., \& Christakis, D. A. (2010). An evaluation of the distribution of sexual references among "Top 8" MySpace Friends. Journal of Adolescent Health, 47(4), 418420.

Moreno, M. A., Christakis, D. A., Egan, K. G., Brockman, L. N., \& Becker, T. (2011). Associations between displayed alcohol references on facebook and problem drinking among college students. Archives of Pediatrics and Adolescent Medicine, 166(2), 157-163.

Moreno, M. A., Cox, E. D., Young, H. N., \& Haaland, W. (2015). Underage college students' alcohol displays on facebook and real-time alcohol behaviors. Journal of Adolescent Health, 56(6), 646-651.

Moreno, M. A., Fost, N. C., \& Christakis, D. A. (2008). Research ethics in the MySpace era. Pediatrics, 121(1), 157-161.

Moreno, M. A., Goniu, N., Moreno, P. S., \& Diekema, D. (2013). Ethics of social media research: Common concerns and practical considerations. Cyberpsychology, Behavior, and Social Networking, 16(9), 708713. doi:10.1089/cyber.2012.0334

Moreno, M. A., Grant, A., Kacvinsky, L., Egan, K. G., \& Fleming, M. F. (2012). College students' alcohol dis- 
plays on Facebook: intervention considerations. Journal of American College Health, 60(5), 388-394. doi:10.1080/07448481.2012.663841

Moreno, M. A., Grant, A., Kacvinsky, L., Moreno, P. S., \& Fleming, M. F. (2012). Older adolescents' views regarding participant in Facebook research. Journal of Adolescent Health, 51, 439-444.

Moreno, M. A., Kacvinsky, L. E., Pumper, M. A., Wachowski, L., \& Whitehill, J. M. (2014). Associations between social media displays and event-specific alcohol consumption by college students. Wisconsin Medical Journal, 112, 251-256.

Moreno, M. A., Kota, R., Schoohs, S., \& Whitehill, J. M. (2013). The Facebook influence model: A concept mapping approach. Cyberpsychology, Behavior, and Social Networking, 16(7), 504-11. doi:10.1089/ cyber.2013.0025

Moreno, M. A., Parks, M., \& Richardson, L. P. (2007). What are adolescents showing the world about their health risk behaviors on MySpace? Medscape General Medicine, 9(4), 9. Retrieved from http://www. ncbi.nlm.nih.gov/entrez/query.fcgi?cmd=Retrieve \&d $\mathrm{b}=$ PubMed\&dopt=Citation\&list_uids $=18311359$

Moreno, M. A., Parks, M. R., Zimmerman, F. J., Brito, T. E., \& Christakis, D. A. (2009). Display of health risk behaviors on MySpace by adolescents: Prevalence and associations. Archives of Pediatrics and Adolescent Medicine, 163(1), 35-41.

Moreno, M. A., Vanderstoep, A., Parks, M. R., Zimmerman, F. J., Kurth, A., \& Christakis, D. A. (2009). Reducing at-risk adolescents' display of risk behavior on a social networking web site: A randomized controlled pilot intervention trial. Archives of Pediatrics and Adolescent Medicine, 163(1), 35-41.

Mundt, M., Mercken, L., \& Zakletskaia, L. (2012). Peer selection and influence effects on adolescent alcohol use: A stochastic actor-based model. BMC Pediatrics, 12(1), 115.

Neighbors, C., Atkins, D. C., Lewis, M. A., Lee, C. M., Kaysen, D., Mittmann, A., . . Rodriguez, L. M. (2011). Event-specific drinking among college students. Psychology of Addictive Behaviors, 25(4), 702-707. doi:10.1037/a0024051

Nicholls, J. (2012). Everyday, everywhere: Alcohol marketing and social media-current trends. Alcohol and Alcoholism, 47(4), 486-493. doi:10.1093/alcalc/ags043

Palfrey, J., \& Gasser, U. (2012). Born digital. Jackson, TN: Basic Books.

Park, B. K., \& Calamaro, C. (2013). A systematic review of social networking sites: innovative platforms for health research targeting adolescents and young adults. Journal of Nursing Scholarship, 45(3), 256264. doi:10.1111/jnu.12032

Robinson, T. N., Chen, H. L., \& Killen, J. D. (1998). Television and music video exposure and risk of adolescent alcohol use. Pediatrics, 102(5), E54. Retrieved from http://www.ncbi.nlm.nih.gov/entrez/query.fcgi?cmd
$=$ Retrieve $\& \mathrm{db}=$ PubMed\&dopt=Citation\&list_uids $=97$ 94984

Signorini, A., Segre, A. M., \& Polgreen, P. M. (2011). The use of Twitter to track levels of disease activity and public concern in the U.S. during the Influenza A H1N1 pandemic. PLoS One, 6(5), e19467.

Sixsmith, J., \& Murray, C. D. (2001). Ethical issues in the documentary data analysis of Internet posts and archives. Qualitative Health Research, 11(3), 423-432. Retrieved from http://www.ncbi.nlm.nih.gov/entrez/ query.fcgi?cmd=Retrieve \&db=PubMed\&dopt=Citatio n\&list_uids $=11339083$

Steinfield, C., Ellison, N. B., \& Lampe, C. (2008). Social capital, self-esteem, and use of online social network sites: A longitudinal analysis. Journal of Applied Developmental Psychology, 29(6), 434-445. doi:10. 1016/j.appdev.2008.07.002

Titus-Ernstoff, L., Dalton, M. A., Adachi-Mejia, A. M., Longacre, M. R., \& Beach, M. L. (2008). Longitudinal study of viewing smoking in movies and initiation of smoking by children. Pediatrics, 121(1), 15-21.

Trochim, W., \& Kane, M. (2005). Concept mapping: An introduction to structured conceptualization in health care. International Journal for Quality in Health Care, 17(3), 187-191. doi:10.1093/intqhc/ mzi038

Valenzuela, S., Park, N., \& Kee, K. F. (2009). Is there social capital in a social network site?: Facebook use and college students' life satisfaction, trust, and participation. Journal of Computer-Mediated Communication, 14(4), 875-901. doi:10.1111/j.1083-6101.200 9.01474.x

West, J. H., Hall, P. C., Hanson, C. L., Prier, K., GiraudCarrier, C., Neeley, E. S., \& Barnes, M. D. (2012). Temporal variability of problem drinking on Twitter. Open Journal of Preventive Medicine, 2(1), 43-48.

Whitehill, J. M., Brockman, L. N., \& Moreno, M. A. (2013). "Just talk to me": Communicating with college students about depression disclosures on facebook. Journal of Adolescent Health, 52(1), 122-127.

Whitehill, J. M., Moreno, M. A., \& Rivara, F. P. (2014). Patterns in drunk-driving references on Twitter: $A$ content analysis. Paper presented at the Research Society on Alcoholism, Bellvue, Washington.

Winpenny, E. M., Marteau, T. M., \& Nolte, E. (2013). Exposure of children and adolescents to alcohol marketing on social media websites. Alcohol and Alcoholism, 49(2):154-159. doi:10.1093/alcalc/agt174

Zhao, Y. X., Liu, J., Tang, J., \& Zhu, Q. H. (2013). Conceptualizing perceived affordances in social media interaction design. Aslib Proceedings, 65(3), 289-302. doi: 10.1108/00012531311330656

Zimmer, M. (2010). "But the data is already public": On the ethics of research in Facebook. Ethics and Information Technology, 12(4), 313-325. doi:10.1007/s1 0676-010-9227-5 


\section{About the Authors}

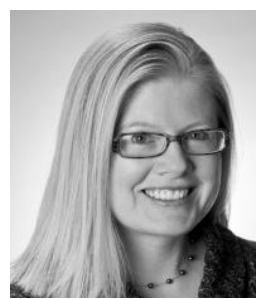

\section{Dr. Megan A. Moreno}

Megan A. Moreno, MD, MSEd, MPH is an Associate Professor of Pediatrics and an adjunct Associate Professor of Health Services at the University of Washington School of Medicine. She is Principle Investigator of the Social Media and Adolescent Health Research Team (SMAHRT) at Seattle Children's Research Institute. Dr Moreno's training includes a MD from George Washington University, a Master's in Education from the University of Wisconsin-Madison and a Master's in Public Health from the University of Washington.

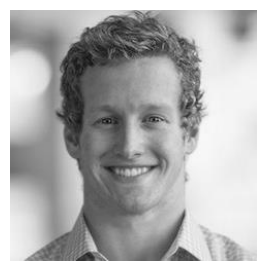

\section{Jon D’Angelo}

Jon D'Angelo is a PhD student at the University of Wisconsin in the Department of Communication Arts, an Associate Lecturer in Education with the Masters for Professional Educators Program located in the Educational Psychology Department within the University of Wisconsin's School of Education, and an Adjunct Lecturer in Communication Studies at Edgewood College in Madison, WI.

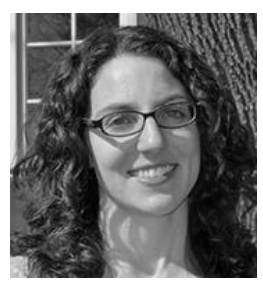

\section{Dr. Jennifer Whitehill}

Jennifer Whitehill is an Assistant Professor at the University of Massachusetts-Amherst. Her training includes a PhD from Johns Hopkins and a postdoctoral fellowship at the University of Washington. Her work focuses on understanding the role of new media technologies such as mobile devices and social networking sites as both a risk factor for injury and as a possible avenue for prevention. 